\title{
Nuevos tiempos para proyectos de intervención socio-educativa en Nicaragua
}

\author{
"Porque llega el momento en que han de cantar nuevos himnos lenguas de gloria" \\ Rubén Darío
}

Graciela Farrach ${ }^{1}$

Nicaragua hoy vive nuevos tiempos. Atrás han quedado los años de gobiernos neoliberales, de economías pensadas en favorecer a la clase empresarial, de empobrecimiento y saqueo a los bienes del estado. Con el triunfo del gobierno del Comandante Daniel Ortega Saavedra, se ha consensuado un Modelo de Gobierno Cristiano, Socialista y Solidario, que plantea un cambio de valores, actitudes, prioridades, estilo de gobierno, relaciones de poder y políticas. La finalidad de estas políticas es el desarrollo integral del ser humano y las familias nicaragüenses, en sus condiciones históricas, culturales, sociales y de políticas nacionales y regionales del presente siglo.

Partiendo de este contexto, podemos decir que nuestro país está experimentando cambios sustanciales en todos los ámbitos, y la educación no es la excepción. Esos "nuevos tiempos" a los que alude Murillo (2013), son tiempos de oportunidades para la planificación y ejecución de proyectos de intervención socio-educativa en Nicaragua.

El Ministerio de Educación cuenta con el Plan Estratégico de Educación 2011-2015, en el que se plantean una serie de acciones con los subsistemas de educación básica, media, superior y técnica; a fin de mejorar el proceso educativo y construir en conjunto un sistema educativo coherente, integral y complementario.

Un claro ejemplo de esto es la Política Nacional para la Primera Infancia "Amor para los más chiquitos y chiquitas”, que forma parte del Sistema Nacional de Bienestar Social y tiene como objetivo fundamental la realización de acciones para la restitución de derechos, mejorar las prácticas de crianza, cuido y protección a la niñez de 0 a 6 años. El solo hecho de que esta sea una política nacional, y no un programa aislado, permite el cumplimiento de la misma a través de la coordinación interinstitucional entre el MINED, MINSA y MIFAM.

Además de la intervención de las instituciones estatales, la comunidad juega un papel fundamental en la realización de acciones contenidas en el programa Amor para los más chiquitos y chiquitas. Precisamente, el Modelo del Poder Ciudadano impulsa la participación protagónica de la comunidad, restituyéndole su derecho de voz y voto en la toma de decisiones trascendentales para la nación.

El programa en mención es sólo uno de los que impulsa el Gobierno, pero quizás uno de los más importantes por el hecho de potenciar las capacidades la niñez, con actividades pedagógicas curriculares y espacios su para el desarrollo integral.

1 Estudiante de Doctorado en Educación e Intervención Social en UNAN-Mangua. Correo Electrónico: gfarrach@gmail.com 
Yéndonos al otro extremo, pasamos a comentar sobre la educación universitaria. Esta ha sido víctima de los gobiernos neoliberales, al punto de tener que recurrir a protestas para recibir de forma parcial el presupuesto anual destinado por ley, lo que costó la sangre de estudiantes y trabajadores.

Afortunadamente ese sombrío panorama es cosa del pasado, pues desde 2007 el 6\% del Presupuesto General de la República se ha garantizado a las universidades públicas. Esta es una gran oportunidad para las instituciones de estudios superiores subsidiadas por el estado, y se traduce en inversiones para el mejoramiento de la calidad educativa, infraestructura, laboratorios, becas, entre otras. Esto beneficia a la sociedad en general, pues las inversiones en educación regresan a la comunidad a través de profesionales capacitados en conocimientos científicos y valores morales; dispuestos a servir desde sus competencias, en la resolución de problemas y aportar al desarrollo socioeconómico del país.

Por lo expuesto, podemos concluir que Nicaragua cuenta con facilidades contextuales y muchas oportunidades para continuar realizando proyectos de intervención social. Los nuevos tiempos llegaron, como lo auguró Darío en el poema Salutación del optimista. En nuestras manos está asumir un rol activo y participativo en la ejecución de las acciones propuestas, a fin de construir juntos la nación anhelada por nuestros héroes y mártires.

\section{BIBLIOGRAFÍA}

GobiernodeReconciliaciónyUnidadNacionalUnidaNicaraguaTriunfa(2011)PolíticaNacionaldePrimera Infancia Amor por los más Chiquitos y Chiquitas. Recuperado de http://www.mined.gob.ni/index. php?option $=$ com_content\&view $=$ article $\&$ id $=667 \% 3$ Achiquits \&catid $=96 \% 3$ Avarios $\&$ Itemid $=55$

MINED (2011) Plan estratégico de Educación 2011-2015. Recuperado de http://www.mined.gob.ni/ Documents/Document/2013/pee2011 2015.pdf.

Murillo, R (2013) Los nuevos tiempos. Managua: Consejo de Comunicación y Ciudadanía. 